\title{
Ações implementadas no regime remoto ofertado por uma escola do sistema municipal de ensino de Brumadinho/MG para a garantia da continuidade da educação em resposta a pandemia
}

\author{
Gislene Silva Dutra ${ }^{1}$ (D) \\ Juliana Machado Anastácio Souza ${ }^{2}$ (D) \\ ${ }^{1}$ Prefeitura de Brumadinho, Minas Gerais; ${ }^{2}$ Universidade Federal de Minas Gerais (UFMG), Brasil
}

Resumo. A pandemia da COVID-19 trouxe inúmeros desafios para todos os setores, no Brasil e no mundo. Na tentativa de reduzir a ampla disseminação do novo Coronavírus, ações de distanciamento social foram adotadas. Na educação, o distanciamento social provocou a suspensão do funcionamento regular das instituições educacionais. Objetiva-se com o presente estudo discutir a efetividade das ações implementadas no regime de estudos remoto para a garantia da continuidade da educação em resposta à pandemia pelo Sistema Municipal de Ensino de Brumadinho/MG. Para tanto, foi realizado um estudo de caso numa escola da rede municipal, localizada na sede do município que atende aos anos finais do Ensino fundamental. Dentre os principais resultados foi possível verificar que os cadernos de atividades utilizados no regime de estudos remoto foram considerados por alunos e professores como uma importante ferramenta na condução do ensino. Contudo, há pontos que precisam ser revistos para buscar uma aprendizagem mais efetiva nessa modalidade de ensino.

Palavras-chave: pandemia; coronavírus; distanciamento social; regime de estudos remoto.

Acciones implementadas en la modalidad remota ofertada por una escuela de sistema municipal de enseñanza de Brumadinho/MG para la garantía de la continuidad de la educación en respuesta a la pandemia

Resumen. La pandemia del COVID-19 trajo numerosos desafíos para todos los sectores, en Brasil y en el mundo. Con el objetivo de reducir la amplia diseminación del nuevo Coronavirus acciones y distanciamiento social fueron adoptadas. En educación el distanciamiento social causó la suspensión del funcionamiento regular de las instituciones educativas. El objetivo del presente estudio es discutir la efectividad de las acciones implementadas en la modalidad remota de estudios para asegurar la continuidad de la educación en respuesta a la pandemia por el Sistema Municipal de Ensino de Brumadinho/MG. Para estos fines se realizó un estudio de caso en una escuela de la red municipal, ubicada en la sede del municipio que atiende los últimos años de la enseñanza secundaria. Entre los principales resultados se pudo verificar que los cuadernos de actividades utilizados en la modalidad remota de estudios fueron considerados por alumnos y profesores como una importante herramienta en la conducción de la enseñanza. Sin embargo, hay puntos que necesitan revisión para buscar un aprendizaje más efectivo por medio de esa modalidad de enseñanza.

Palabras clave: pandemia; coronavirus; distanciamento social; educación en línea.

Actions implemented in the remote system offered by a school in the municipal education system of Brumadinho/MG to guarantee the continuity of education in response to the pandemic

Abstract. The COVID-19 pandemic has brought numerous challenges to all sectors, in Brazil and worldwide. In an attempt to reduce the widespread spread of the new Coronavirus, actions of social detachment were adopted. In education, social detachment caused the suspension of the regular functioning of educational institutions. The aim of this study is to discuss the effectiveness of the actions implemented in the remote study regime to guarantee the continuity of education in response to the pandemic by the Municipal Education System of Brumadinho / MG. To this end, a case study was carried out in a municipal school, located at the headquarters of the municipality that serves the final years of elementary school. Among the main results, it was possible to verify that the activity notebooks used in the remote study regime were considered by students and teachers as an important tool in the conduct of teaching. However, there are points that need to be reviewed in order to seek more effective learning in this type of teaching.

Keywords: pandemic; coronavirus; social distancing; remote study scheme. 


\section{Introdução}

A pandemia da COVID-19 trouxe inúmeros desafios para todos os setores, no Brasil e no mundo, exigindo de todos os segmentos o cumprimento de medidas de segurança para conter a proliferação do vírus. Na tentativa de reduzir a ampla disseminação do novo Coronavírus, ações de distanciamento social foram adotadas.

\section{Conforme aponta Lima (2021, p. 3)}

Uma ruptura no tecido social que nos acolhe e nos dá as bases simbólicas de pensamento e instrumentação para ação, acaba por provocar instabilidade no funcionamento do sistema emocional que, por sua vez, pode impactar a saúde do próprio corpo.

Na educação, o distanciamento social provocou em muitos sistemas de ensino a suspensão do funcionamento regular das instituições educacionais ocasionando impactos previsíveis nas oportunidades de aprendizagem.

São poucas as informações, baseadas em evidências, sobre os efeitos da pandemia com suspensão das aulas ou com medidas alternativas de educação, seus impactos na aprendizagem e na eficácia das ações de contenção utilizadas pelas escolas.

As aulas presenciais no Sistema Municipal de Ensino do município de Brumadinho/MG iniciaram-se em 04 de fevereiro de 2020 e foram suspensas no dia 16 de março de 2020, ficando sem a implementação de arranjos alternativos para a continuidade educacional até o dia 09 de junho do mesmo ano.

Diante disso, apresenta-se como problema dessa pesquisa, a seguinte questão: que inovações foram implementadas nas escolas municipais de Brumadinho/MG para garantir a continuidade da educação em resposta à Pandemia e que efetividade tiveram?

Objetiva-se com o presente estudo discutir a efetividade das ações implementadas no regime remoto para a garantia da continuidade da educação em resposta à pandemia numa escola que atende os anos finais do Ensino Fundamental do Sistema Municipal de Ensino de Brumadinho/MG, aqui nomeada de EMPM.

No primeiro momento se apresenta uma contextualização do município de Brumadinho e da organização do seu sistema de ensino. Em seguida, foi realizada uma descrição das ações implementadas pela rede municipal para garantir a continuidade da educação em resposta à Pandemia. Por fim, apresentaram-se os resultados do levantamento das percepções dos professores e dos alunos do $9^{\circ}$ ano do Ensino Fundamental da EMPM sobre a efetividade do regime remoto adotado no ano de 2020.

\section{Metodologia}

Nossa pesquisa tem natureza aplicada e abordagem qualitativa. Segundo Paiva, a pesquisa aplicada "tem por objetivo gerar novos conhecimentos, mas tem por meta resolver problemas, inovar ou desenvolver novos processos e tecnologias" (Paiva, 2019, p. 11).

Aabordagem qualitativa nos possibilitou analisar e refletir sobre os dados gerados por meio de questionários, interpretando os procedimentos adotados pela EMPM para garantir a continuidade do ensino, de forma remota, em meio aos desafios impostos pela pandemia de coronavírus, em 2020. 
Para desenvolver este artigo elegemos o estudo de caso como o método de pesquisa mais viável. Segundo Paiva (2019, p.65)

O estudo de caso é um tipo de pesquisa que investiga um caso particular constituído de um indivíduo ou grupo de indivíduos em um contexto específico. É um estudo naturalístico porque estuda um acontecimento em um ambiente natural e não criado para a pesquisa.

Em visão semelhante, Leffa (2006, p.56) refere-se ao estudo de caso como uma metodologia representativa da pesquisa qualitativa, uma "investigação profunda e exaustiva de um participante ou pequeno grupo", que visa a uma análise de todas as informações específicas e relevantes ao tema em estudo. Para tanto, o autor recomenda a utilização de procedimentos diversos, como entrevistas, questionários, gravações de áudio, entre outros, com o intuito de ultrapassar a investigação de uma variável determinada e descrever aspectos que envolvem a situação, em sua totalidade.

Leffa (2006) acrescenta que o estudo de caso se preocupa em explorar e descrever minuciosamente determinado evento, chamando a atenção para dois importantes aspectos: sua isenção em descobrir verdades universais (visto que, como método intuitivo, a teoria dá-se por observações empíricas) e aplicação à educação como técnica de ensino.

Conforme as recomendações do autor, no estudo de caso descrito neste artigo adotamos procedimentos como a aplicação de questionários e a análise documental como meios para gerar dados e, posteriormente, investigá-los. Os questionários foram elaborados a partir de questões objetivas, com o intuito de traçar um perfil dos grupos contemplados na pesquisa, e questões discursivas, cuja análise nos possibilitou conhecer melhor e analisar suas percepções sobre o regime de estudos remoto implementado na EMPM em 2020.

Visando alcançar maior abrangência no momento de distanciamento social, e em respeito às recomendações para tal, utilizamos a ferramenta formulários do google para criar os questionários e enviá-los aos estudantes e aos professores, por meio de um link, em grupos de WhatsApp, de modo que cada participante possa dar suas respostas e enviá-las às pesquisadoras.

Os participantes deste estudo foram dois grupos específicos da EMPM, envolvidos diretamente nas ações do regime de estudos remotos, a saber: os estudantes do $9^{\circ}$ ano e os docentes de todas as disciplinas em turmas regulares do $6^{\circ}$ ao $9^{\circ}$ ao do ensino fundamental II.

A escolha dos primeiros se deu por três motivos: a certa maturidade apresentada pelos estudantes do $9^{\circ}$ ano na realização das atividades implementadas durante o ensino remoto; a ampla participação e interação com os professores, por meio de grupos de WhatsApp, ferramenta utilizada para lançar perguntas e sanar dúvidas em conversas ou áudios explicativos; o resultado satisfatório na devolutiva dos cadernos de atividades remotas para apreciação dos professores.

Além disso, 2020 foi o último ano desses alunos nesta escola, visto que a instituição não atende o ensino médio, nível para o qual seguirão no próximo ano. Tendo esclarecido o método de pesquisa, os procedimentos adotados para a sua execução e os participantes envolvidos, passamos ao seu desenvolvimento. 


\section{Contextualização do município e do sistema municipal de ensino}

O município de Brumadinho/MG é considerado de pequeno porte e faz parte da Região Metropolitana de Belo Horizonte. Situado a $60 \mathrm{~km}$ da capital, nas encostas do Quadrilátero Ferrífero - delimitação de uma área economicamente ligada à extração do minério de ferro - e em parte, na depressão onde se localiza o Vale do Rio Paraopeba. De acordo com o censo de 2020, o município mineiro possui atualmente 33.973 mil habitantes.

Figura 1. Localização do município no estado na região metropolitana de Belo Horizonte/MG

\section{Brumadinho}

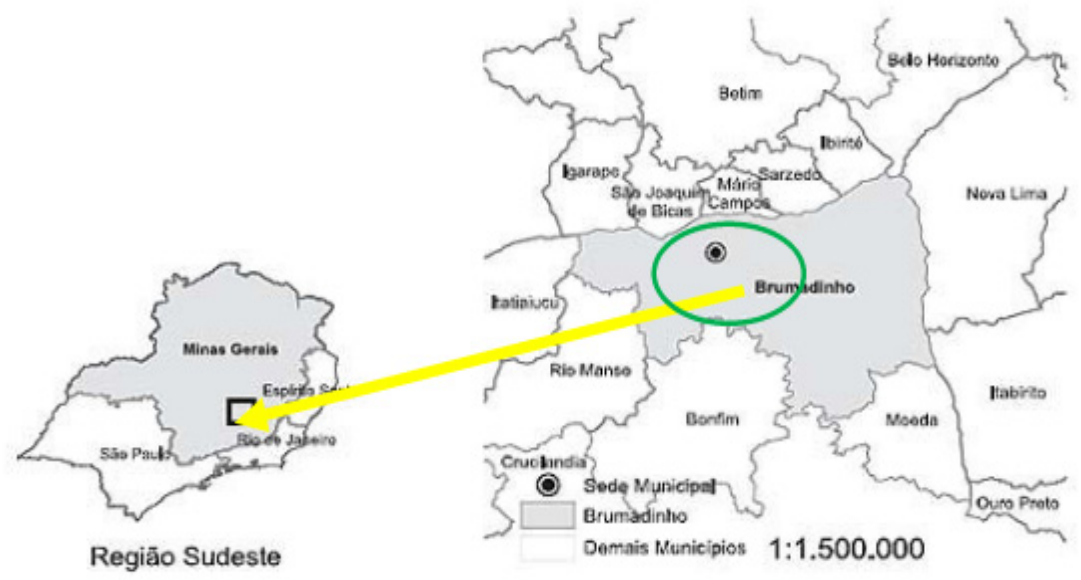

Fonte: Brumadinho (2015)

A partir da definição de município como ente federado autônomo, nos termos da Constituição de 1988, muitas ações se desenvolveram em todo o País, buscando exercer essa autonomia de forma a descentralizar a política administrativa.

A Lei das Diretrizes e Bases da Educação Nacional (Brasil, 1996) prevê a possibilidade de criação dos Sistemas Municipais de Ensino, integrados às políticas e planos educacionais da União e dos Estados. Nesse contexto, em 28 de abril de 2006, foi sancionada a Lei $n^{\circ}$ 1539/2006, que instituiu o Sistema Municipal de Ensino de Brumadinho, rerratificada pela Lei 1.550/2006 (Brumadinho, 2015).

O Sistema Municipal de Ensino de Brumadinho é composto por escolas públicas municipal, estadual e privadas. A rede pública atende à Educação Básica e a rede Privada atende à Educação Básica e Superior (Brumadinho, 2015).

De forma mais detalhada, o Sistema Municipal de Ensino é composto por escolas de Educação Infantil, unidade de Ensino Fundamental, mantidas pelo poder público municipal, escolas privadas de educação infantil, situadas no município de Brumadinho, órgãos executivos municipais de educação e órgão normativo do Sistema. O município possui uma grande extensão territorial, com área de $639,43 \mathrm{~km}^{2}$. Assim, as escolas se localizam em diversos pontos do município, algumas delas ficam a 36 
km da sede do mesmo. São 12 escolas localizadas na zona rural e 8 na sede do município. A figura 2 mostra a localização das escolas na Zona Rural do município.

Figura 2. Localização das escolas na zona rural do município

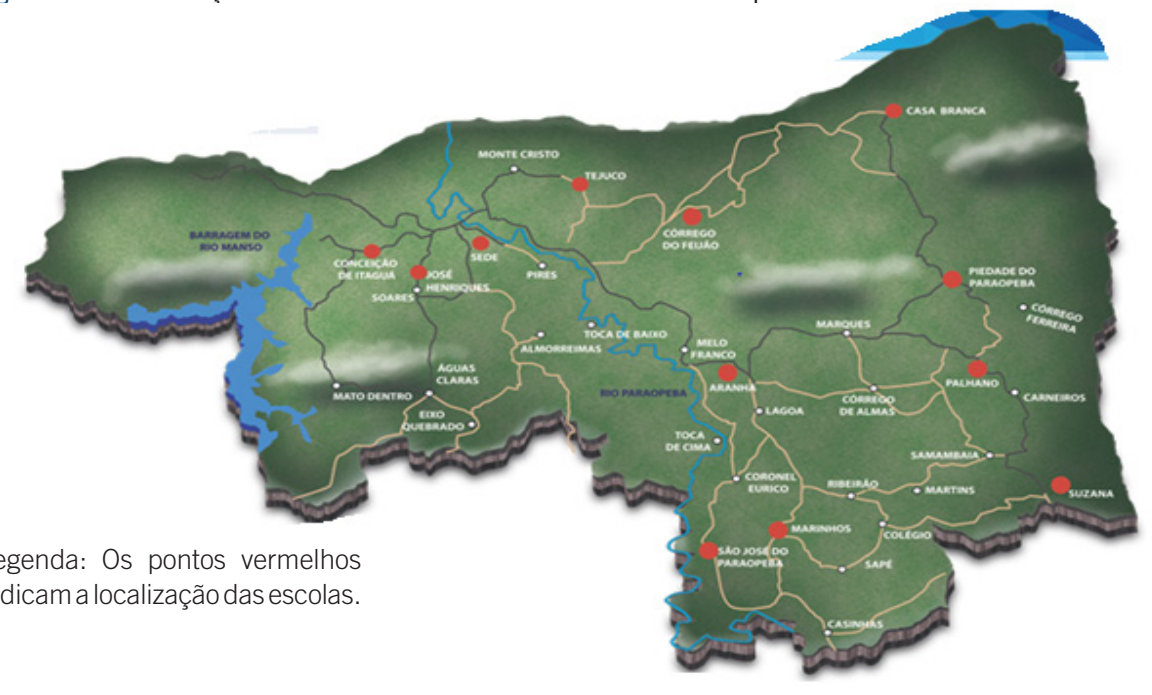

Fonte: Brumadinho (2015).

Figura 3. Localização das escolas na sede do município

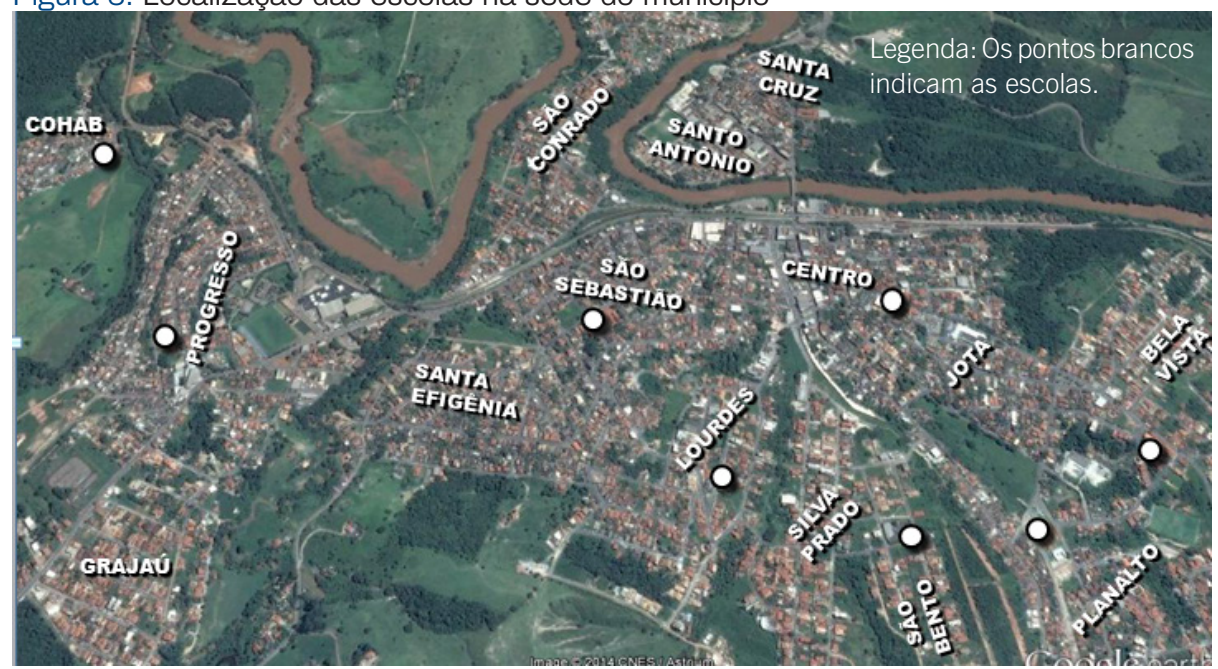

Fonte: Brumadinho (2015)

De acordo com o censo educacional de 2020, as escolas municipais atendem 6.165 alunos da Educação Infantil aos anos finais do Ensino Fundamental (6 $6^{\circ}$ ao $9^{\circ}$ anos). 


\subsection{Atividades educacionais remotas das escolas municipais de Brumadinho, em meio à pandemia da COVID-19, no ano de 2020.}

As aulas presenciais na Rede municipal de Brumadinho/MG iniciou-se em 04 de fevereiro de 2020 e foi suspensa no dia 16 de março de 2020, ficando sem nenhuma ação educacional até o dia 09 de junho do mesmo ano.

A partir de junho, a rede municipal fez a adoção de atividades pedagógicas remotas (a serem entregues em forma de um caderno impresso), seguindo a orientação do Conselho Estadual de Educação (CEE) que dispôs a Resolução 474 de 08/05/2020, publicada no jornal Minas Gerais em 30/05/2020, pag. 29, em seu artigo 4․

Art $4^{\circ}$ - Entende-se por atividades pedagógicas não presenciais aquelas a serem realizadas, pela instituição de ensino, com os estudantes, quando não for possível a presença físicas desses, no ambiente escolar. Assim sendo, as atividades pedagógicas não presenciais podem acontecer por meios digitais (videoaulas, conteúdos organizados em plataformas virtuais de ensino e aprendizagem, redes sociais, correio eletrônico, blogs, entre outros), por meio de programas de televisão ou rádio; pela adoção de material didático impresso, com orientações pedagógicas, distribuindo aos alunos e seus pais ou responsáveis e pela orientação de leituras, projetos, pesquisas, atividades e exercícios indicados nos materiais didáticos. A comunicação é essencial, nesse processo, assim como a elaboração de guias de orientação das rotinas de atividades educacionais não presenciais para orientar famílias e estudantes, sob a supervisão de professores e dirigentes escolares. (CEE, 2020)

Por solicitação da Secretaria Municipal de Educação, uma enquete com os profissionais da educação sobre quais as estratégias poderiam ser adotadas no regime remoto foi realizada nas escolas da Rede Municipal, com as seguintes questões:

1. De que forma serão realizadas as atividades remotas na Rede Municipal de Brumadinho?

2. Qual destas estratégias será a mais adequada, a princípio, como a melhor forma de acesso a todos os mais de 6.000 alunos da rede municipal de Brumadinho?

3. Será através de material impresso, utilizando-se todas as medidas sanitárias para evitar risco de contaminação do coronavírus?

4. Estas atividades devem retornar ao professor? Como? Quando?

5. A correção das atividades é importante para dar continuidade ao desenvolvimento do currículo?

6. Vão entregar as atividades na escola ao final do prazo estipulado para as realizarem? Ou ao final do período de suspensão das aulas?

A partir dos resultados da enquete, foram previstas as seguintes estratégias (figura 4) para a implementação do regime remoto nas escolas da rede municipal. 
Figura 4. Estratégias de implementação do Regime Remoto nas escolas municipais.

1. Reunião on-line dos supervisores e diretores com os professores para esclarecimento do plano de ação e solicitar a elaboração das atividades para envio aos alunos, pais ou responsáveis.

2. Levantamento, pelos professores, dos alunos que possuem internet em casa e meios tecnológicos para receber as atividades (celular, tablet, computador, etc.).

3. Elaboração das atividades para envio aos alunos on-line ou material impresso para aqueles que não têm acesso à internet.

Entrega das atividades impressas nas datas estipuladas no quadro 1 , respeitando o protocolo da Organização Mundial de Saúde e da Secretaria Municipal de Saúde.

5. Retorno das atividades realizadas e o recebimento de novas atividades, conforme data discriminada no quadro 1.

6. O estudante que tiver dúvidas ao realizar as atividades poderá esclarecê-las junto ao professor, dentro do seu horário de trabalho, por meio de estratégias (e-mail, vídeo, Whatsapp, etc) criadas pelo professor juntamente com a equipe escolar.

Fonte: Brumadinho (2020)

A Secretaria Municipal de Educação elaborou um cronograma (quadro 1) para a entrega das atividades remotas, adotado em todas as escolas da rede municipal. $\mathrm{O}$ cronograma dispunha de datas definidas para os pais/responsáveis retirar e devolver o caderno de atividades nas escolas.

Quadro 1. Cronograma de entrega das atividades remotas nas escolas municipais de Brumadinho/MG

\begin{tabular}{cccc}
\hline \multicolumn{2}{c}{ Pais } & \multicolumn{2}{c}{ Professores } \\
\hline Entrega de atividades & $\begin{array}{c}\text { Devolução de ativi- } \\
\text { dades }\end{array}$ & $\begin{array}{c}\text { Entrega de atividades } \\
\text { para supervisora }\end{array}$ & $\begin{array}{c}\text { Devolução de ativida- } \\
\text { des para professor }\end{array}$ \\
\hline $09 / 06 / 2020$ & --- & $04 / 06 / 2020$ & $23 / 06 / 2020$ \\
$16 / 06 / 2020$ & $16 / 06 / 2020$ & $10 / 06 / 2020$ & $07 / 07 / 2020$ \\
$30 / 06 / 2020$ & $30 / 06 / 2020$ & $24 / 06 / 2020$ & $21 / 07 / 2020$ \\
$14 / 07 / 2020$ & $14 / 07 / 2020$ & $09 / 07 / 2020$ & $04 / 08 / 2020$ \\
$28 / 07 / 2020$ & $28 / 07 / 2020$ & $23 / 07 / 2020$ & $18 / 08 / 2020$ \\
$11 / 08 / 2020$ & $11 / 08 / 2020$ & $06 / 08 / 2020$ & $01 / 09 / 2020$ \\
$25 / 08 / 2020$ & $25 / 08 / 2020$ & $20 / 08 / 2020$ & --- \\
--- & $08 / 09 / 2020$ & --- & --- \\
\hline
\end{tabular}

Fonte: Brumadinho (2020).

A Medida Provisória n 934 de 01/04/2020 flexibilizou o cumprimento dos 200 dias letivos (Brasil, 2020), mas permaneceu com a obrigatoriedade de cumprimento das 800 horas de atividades escolares, podendo as aulas remotas serem computadas nestas horas. Diante disso, a Secretaria Municipal de Educação organizou a carga 
horária do ano letivo de 2020 do Sistema de Ensino conforme expresso no quadro 2. Para tanto, ficou definido que o cômputo da carga horária seria efetivado mediante a devolução dos blocos de atividades nas datas previstas no cronograma (quadro 2).

Quadro 2. Cômputo da carga horária

\begin{tabular}{lccc}
\hline \multicolumn{1}{c}{ Atividades } & & & Carga horária \\
\hline Aulas presenciales & $(05 / 02$ á 17/03/2020) & Presencial & $112: 30$ \\
\hline Bloco/caderno I & $09 / 06 / 2020$ & $16 / 06 / 2020$ & $44: 30$ \\
Bloco/caderno II & $16 / 06 / 2020$ & $30 / 06 / 2020$ & $44: 30$ \\
Bloco/caderno III & $30 / 06 / 2020$ & $14 / 07 / 2020$ & $44: 30$ \\
Bloco/caderno IV & $14 / 07 / 2020$ & $28 / 07 / 2020$ & $44: 30$ \\
Bloco/caderno V & $28 / 07 / 2020$ & $11 / 08 / 2020$ & $44: 30$ \\
Bloco/caderno VI & $11 / 08 / 2020$ & $25 / 08 / 2020$ & $44: 30$ \\
Bloco/caderno VII & $25 / 08 / 2020$ & $08 / 09 / 2020$ & $44: 30$ \\
Bloco/caderno VIII & $08 / 09 / 2020$ & $22 / 09 / 2020$ & $52: 30$ \\
Bloco/caderno IX & $22 / 09 / 2020$ & $06 / 10 / 2020$ & $52: 30$ \\
Bloco/caderno X & $06 / 10 / 2020$ & $20 / 10 / 2020$ & $52: 30$ \\
Bloco/caderno XI & $20 / 10 / 2020$ & $03 / 11 / 2020$ & $52: 30$ \\
Bloco/caderno XII & $03 / 11 / 2020$ & $17 / 11 / 2020$ & $52: 30$ \\
Bloco/caderno XIII & $17 / 11 / 2020$ & $01 / 12 / 2020$ & $52: 30$ \\
Bloco/caderno XIV & $01 / 12 / 2020$ & $15 / 12 / 2020$ & $70: 00$ \\
\hline
\end{tabular}

Fonte: Brumadinho (2020).

Assim, ficou definido que os professores deveriam elaborar um caderno de atividades contemplando todas as disciplinas do currículo para serem entregues quinzenalmente para os alunos, de acordo com os conteúdos previstos na proposta curricular do município.

\subsection{Atividades educacionais remotas da EMPM em Brumadinho/MG.}

O Sistema Municipal de Ensino baixou normas gerais para a organização dos arranjos alternativos para a continuidade educacional, mas possibilitou que as escolas fizessem ajustes na implementação de acordo com sua demanda. A escola EMPM se organizou a partir das seguintes etapas de implementação do regime de ensino remoto:

1. Reunião remota da direção/supervisão com os professores para explanação do Plano de Ação Educacional proposto pelo Sistema Municipal de Ensino.

2. Levantamento das demandas e conhecimentos dos docentes referente ao acesso à internet e aos conhecimentos das ferramentas necessárias para o trabalho remoto.

3. Levantamento das demandas e conhecimentos dos discentes sobre o acesso a internet e os conhecimentos das ferramentas necessárias para o trabalho remoto.

4. Formação de grupos de Whatsapp para cada turma, contando com a participação dos alunos, professores referência e da coordenação pedagógica. 
A organização dos cadernos de atividades remotas (figura 5) foi definida em reunião com a coordenação pedagógica (supervisoras) e os professores.

Figura 5. Organização dos cadernos de atividades remotas.

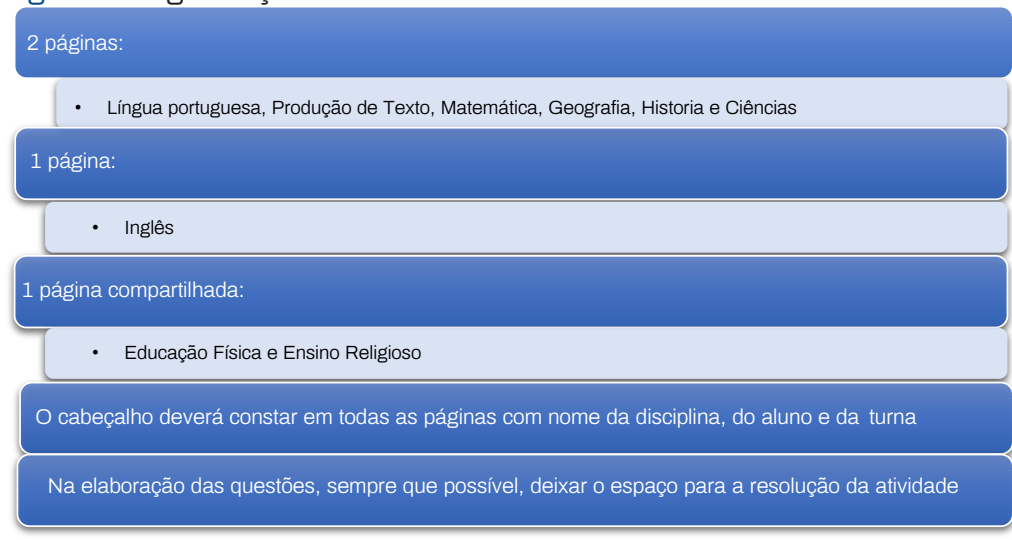

Fonte: Arquivo da EMPM.

Para a elaboração de atividades, os professores foram orientados a situar o conteúdo, explicando-o brevemente e colocando um QR Code com indicações de vídeos e links sobre o tema e, sempre que possível, fazer alusão ao conteúdo no livro didático, especificando as páginas.

A forma de registro de participação dos estudantes foi efetivada a partir de um controle de retirada e entrega das atividades remotas, mediante a coleta de assinatura dos pais/responsáveis.

Além da entrega dos cadernos impressos de atividades remotas, foi criado um grupo de whatsapp para cada turma, contando com a participação dos alunos, professores-referência e da coordenação pedagógica. A função do grupo foi manter a comunicação com os alunos e ter um canal para sanar as dúvidas e atender às suas demandas. O caderno de atividades era postado no grupo para aqueles que não puderam retirá-lo na escola em data prevista.

Quanto à metodologia adotada para o trabalho com os conteúdos, o Sistema Municipal de Ensino deixou livre para iniciativa da escola de acordo com a realidade e possibilidade dos professores. Na EMPM, alguns professores realizaram encontros de correção de atividades por meio de plataformas digitais gratuitas, outros adotaram a gravação de áudios explicativos no grupo de whatsapp, mas a maioria dos profissionais utilizaram, somente, os cadernos de atividades impressos.

A documentação das atividades remotas, adotada pela escola, foram relatórios circunstanciados das ações de aprendizagem dos alunos, contendo a data do referido caderno de atividade, conteúdos desenvolvidos e anexo da atividade remota da referida disciplina. Uma cópia do relatório ficou arquivada na escola e outra encaminhada à Secretaria Municipal de Educação. Além dos referidos relatórios, a gestão escolar adotou uma ficha de controle de recebimento e entrega de atividades por turma. 
Quanto aos processos avaliativos, a escola seguiu as orientações de valorização das atividades propostas pela Secretaria Municipal de Educação (quadro 3).

Quadro 3. Valorização bimestral dos cadernos de atividades remotas

\begin{tabular}{llll}
\hline \multicolumn{1}{c}{$1^{\circ}$ bimestre } & \multicolumn{2}{c}{ Valorização bimestral } \\
\hline Bloco/caderno I & Bloco/caderno V & Bloco/caderno IX & \multicolumn{1}{c}{ Bloco/caderno XIII } \\
5,0 pontos & 5,0 pontos & 5,0 pontos & 10,0 pontos \\
Bloco/caderno II & Bloco/caderno VI & Bloco/caderno X & Bloco/caderno XIV \\
5,0 pontos & 5,0 pontos & 5,0 pontos & 19,0 pontos \\
Bloco/caderno III & Bloco/caderno VII & Bloco/caderno XI & \\
5,0 pontos & 5,0 pontos & 5,0 pontos & \\
Bloco/caderno IV & Bloco/caderno VIII & Bloco/caderno XII & \\
5,0 pontos & 5,0 pontos & 5,0 pontos & \\
\hline
\end{tabular}

Fonte: Brumadinho (2020)

A correção das atividades foi realizada pelo professor de cada disciplina e devolvida à escola para arquivo. A partir da correção, os professores direcionavam o andamento dos conteúdos da próxima atividade.

\subsection{Análise dos questionários de alunos e professores da EMPM sobre o regime de estudo remoto implementado em 2020, em decorrência da pandemia da COVID-19.}

Os dados apresentados a seguir foram gerados a partir das análises das respostas de estudantes e de professores da EMPM, em Brumadinho/MG, ao questionário que investigou suas percepções relacionadas ao regime de estudo remoto adotado no ano de 2020, devido à pandemia de coronavírus que assolou o país à época e que continua sendo um grave problema de saúde pública no Brasil e no mundo.

Por se tratar de um modelo de ensino inédito, em certa medida, tanto para os estudantes, quanto para os professores, ambos acostumados com as aulas presenciais na escola, o intuito do inquérito foi verificar a maneira como os alunos matriculados no $9^{\circ}$ ano do ensino fundamental e os professores da escola se sentiram diante de um cenário inesperado, que interrompeu as atividades escolares de maneira abrupta, impondo a adoção de novas estratégias de ensino e aprendizagem para o momento pandêmico.

A escolha de investigar, por ora, apenas este nível de ensino se deu por dois motivos: a maturidade esperada para os alunos matriculados nesta série para lidar com a nova situação; e, em razão de este ser o último ano desses alunos na EMPM, visto que a instituição atende os alunos do ensino fundamental II.

Os dados apresentados nesta seção foram gerados a partir das respostas de questionários enviados aos dois grupos contemplados na investigação, por meio de um link para um formulário gerado pela ferramenta Google formulários e enviados por grupos de WhatsApp. 
Para apresentar nossas interpretações optamos por organizar a seção em dois subtópicos, que apresentam a composição de cada questionário seguido das análises interpretativas sobre as percepções dos alunos e dos professores, separadamente.

\subsubsection{O regime de estudo remoto na visão dos alunos}

O questionário elaborado para os alunos foi organizado em duas seções, a saber: a) Conhecendo um pouco melhor o perfil do aluno; e b) Suas percepções sobre o regime de estudo da escola, cujo intuito foi o de conhecer melhor as percepções dos estudantes matriculados no $9^{\circ}$ ano do ensino fundamental sobre os dois aspectos elencados acima. Para fins de organização, nossas análises foram norteadas por esses aspectos e serão apresentadas em seguida.

Primeiramente, apresentamos um breve perfil dos estudantes participantes deste inquérito: 42 adolescentes, com idade aproximada de 14 a 16 anos, cujo tempo de estudo nesta instituição escolar varia entre 2 a 5 anos. $O$ fato de todos residirem na sede do município de Brumadinho afasta, em certa medida, a dificuldade em acessar à internet como um dos suportes para a realização das atividades remotas, uma vez que, nas regiões rurais do município este acesso pode ser prejudicado.

Outra informação que merece atenção é o fato de todos os alunos serem beneficiados pelo auxílio emergencial da Vale, com valor aproximado de um quarto do salário mínimo (aproximadamente duzentos e cinquenta reais) para cada criança ou adolescente, doação decorrente do acordo entre a Mineradora e o Ministério Público do Estado de Minas Gerais, como uma ação reparadora do crime que aconteceu na cidade em $2019^{1}$.

De tal forma, é fato que a grande maioria dos estudantes possuem smartphones com tecnologias avançadas e acesso à internet, o que, de certa forma, pode contribuir como um meio de aprendizagem informal, podendo, também, favorecer os estudos remotos.

Quando interrogados sobre a dedicação à realização das atividades constantes dos cadernos de estudos não presenciais, em sua grande maioria, os alunos se autodeclararam muito interessados, embora alguns demonstrassem falta de autonomia ou desorganização pessoal relacionadas com a realização das atividades remotas, reveladas em atitudes como o atraso nas entregas das tarefas escolares ou o descuido na realização delas. Tais atitudes descontroem, em certa medida, a afirmação de muito interesse por parte dos estudantes, já que, o empenho demonstrado na realização e na devolução dos cadernos de atividades remotas não condiz com suas respostas.

Quanto à avaliação das estratégias adotadas pela escola no regime de estudos remoto, os estudantes demonstraram posições divergentes: enquanto, alguns avaliaram as ações como boas estratégias, eficientes na condução dos estudos durante a pandemia, outros consideram o processo como muito ruim ou pouco eficiente. Aqui se percebe uma mistura entre a organização pessoal de cada estudante - ou a falta dela - em relação ao seu comprometimento e dedicação às tarefas escolares, de maneira mais autônoma, e as ações esperadas para a condução do ensino neste novo momento.

\footnotetext{
${ }^{1} \mathrm{O}$ crime a que nos referimos foi ao rompimento da barragem de rejeitos de minério na mina Córrego do Feijão, em Brumadinho/MG, que deixou 270 mortos e 11 não encontrados, em janeiro de 2019, amplamente divulgado nos canais de imprensa do Brasil e de outros países.
} 
Gráfico 1. Como você se considera enquanto aluno?

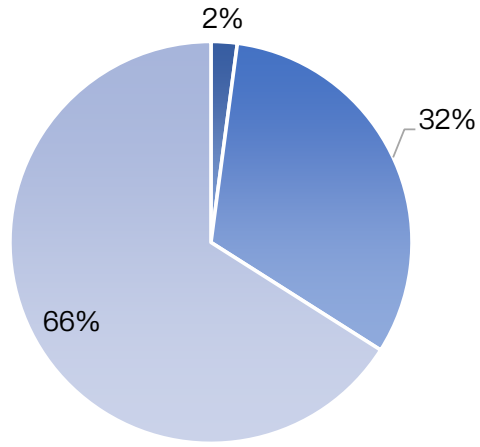

- Muito interessado nos estudos e nas aulas

- Pouco interessado nos estudos e nas aulas

- Nada interessado nos estudos e nas aulas

Fonte: Elaboração própria.

Talvez eles esperassem mais do que a escola foi capaz de oferecê-los naquele momento, seja por falta de recursos tecnológicos, seja por falta de conhecimento dos profissionais que se viram diante de uma situação inesperada e com pouca prática para utilizar novos recursos e implementar práticas pedagógicas mais eficazes para responder às necessidades do processo de ensino e aprendizagem no momento pandêmico. De qualquer modo, não é nossa intenção abrir espaço para julgamentos ou interpretações a priori, visto os desafios impostos à educação, principalmente, às escolas públicas, em criar novas perspectivas para o ensino e aprendizagem de forma remota.

O fato de os estudantes estarem diante de uma situação nova, abrupta e inesperada pode ser uma justificativa para as respostas dadas à próxima questão, relacionada à autoavaliação da aprendizagem alcançada com o regime de estudos remoto (gráfico 2), em que a grande maioria declarou ter aprendido pouco ou menos do que esperavam.

Gráfico 2. Em relação à aprendizagem alcançada nos conteúdos/atividades desenvolvidos no decorrer do ensino remoto emergencial.

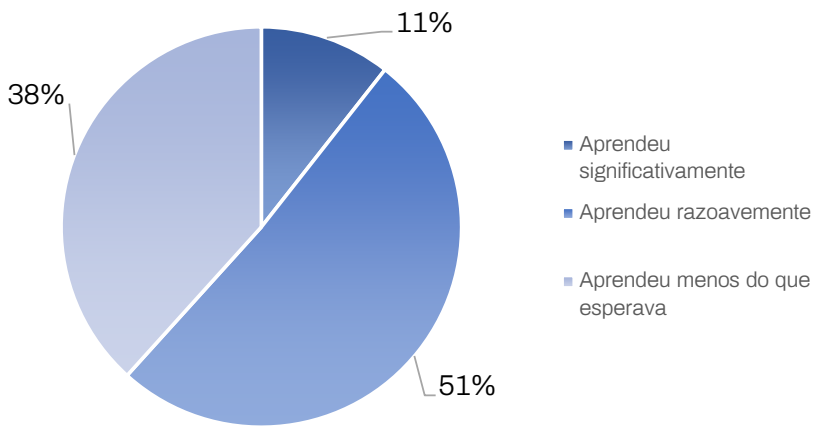

Fonte: Elaboração própria. 
Embora seja uma avaliação pessoal, cabe adiantar a visão dos professores revelada no questionário sobre a percepção dos profissionais relativa ao regime de estudos remotos: mesmo com todos os desafios impostos, muitos deles consideraram que os estudantes tiveram bom desempenho na realização das tarefas, condição revelada tanto na correção das atividades dos alunos, quanto em suas interações com eles por meio de grupos de WhatsApp para sanar alguma dúvida ou oferecer explicações por meio de áudios ou vídeos explicativos.

Tais informações não desmerecem a percepção dos estudantes em relação ao próprio processo de ensino e aprendizagem de forma mais autônoma, contudo, lançam a ideia de que a falta de aprendizagem no período pode estar mais ligada a um sentimento pessoal do que real.

Para os estudantes, outra justificativa para a pouca eficiência da aprendizagem no regime de estudos remotos deve-se à falta da interação presencial com os professores, ou seja, para eles, as explicações que acontecem nos momentos das aulas presenciais são imprescindíveis para gerar uma aprendizagem mais produtiva e eficiente. A nosso ver, trata-se de um sentimento naturalmente compreensível, visto que os estudantes foram afastados da escola abruptamente, sem, ao menos, poderem se preparar para que o processo de aprendizagem acontecesse de forma mais autônoma, sem a participação direta e constante do professor.

Em relação às inovações adotadas pela escola/professores para responder à ausência das aulas presenciais decorrente da pandemia de coronavírus, os recursos tecnológicos citados como os mais produtivos, em escala gradual, foram: a inserção de QR Codes com indicações de conteúdos explicativos relacionados aos conteúdos escolares; a indicação de links para videoaulas; e, por fim, a gravação de áudios e vídeos explicativos enviados por meio do WhatsApp.

Uma vez apontadas pelos próprios estudantes como ações eficientes para o regime de estudos remoto, vale destacá-los como recursos possíveis de serem implementados em um momento tão conturbado para a educação. Nesse sentido, os ressaltamos como recursos acessíveis, que, além de eficientes, são de fácil operacionalização, tanto para os professores, quanto para os alunos.

Contudo, longe de qualquer julgamento que desmereça os esforços da escola e dos seus profissionais em oferecer aos estudantes um ensino qualificado, as respostas de alguns estudantes alertaram para falhas na condução do regime de ensino remoto adotado na escola, como a falta de canais para estabelecer uma comunicação mais efetiva com os professores e a ausência de meios para as aulas remotas síncronas, apontando a necessidade de revisão de aspectos que precisam de ser diagnosticados e melhorados, visando garantir uma aprendizagem mais eficaz em situações como a descrita neste estudo.

Dessa maneira, um dos obstáculos mais apontados para o regime de ensino remoto foi a dificuldade em compreender as atividades sem o auxílio do professor, informação que revela, novamente, as necessidades dos estudantes em interagir com os professores e ouvirem suas explicações para os conteúdos escolares, mesmo virtualmente, por meio de plataformas que oferecem tal possibilidade. 
Gáfico 3. Aspectos que influenciaram de forma negativa no acompanhamento do conteúdo ou atividades implementadas no ensino remoto

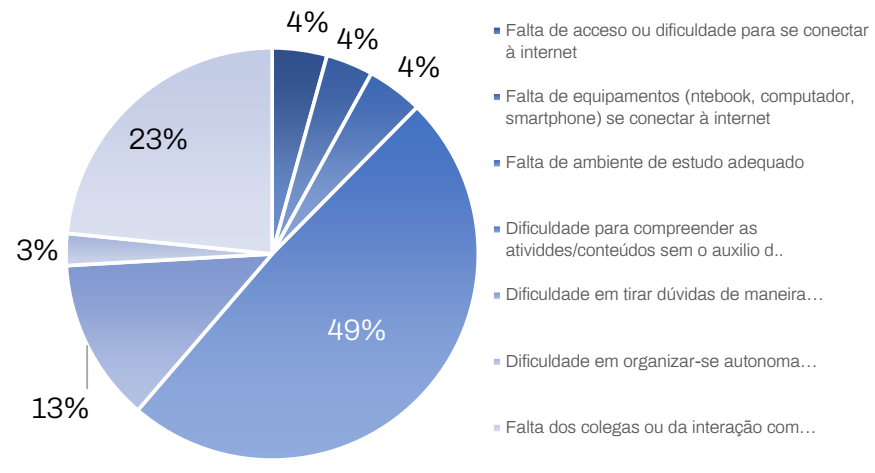

Fonte: Elaboração própria.

Segundo os próprios estudantes, embora tenham se esforçado na realização das atividades e acompanhado as orientações escolares referentes ao regime remoto, isto não foi o suficiente para garantir a aprendizagem tal como ela acontece nas aulas presenciais. Assim, muitos revelaram terem aprendido menos do que esperavam, o que consideramos uma resposta natural frente uma situação inesperada e abrupta como essa.

\subsection{O regime de estudo remoto na visão dos professores}

Gentilmente, 15 professores responderam ao questionário sobre suas percepções sobre o regime de estudos remoto adotado na EMPM em 2020. São professores de componentes curriculares diversos. Grande parte deles compõem o quadro de professores efetivos da escola (60\%), e os outros são profissionais que foram contratados para atuar na escola por meio de processo seletivo simplificado.

Em relação ao tempo de atuação docente, a maioria possui larga experiência no ensino, apresentando mais de 10 anos de trabalho como professores de escola pública, e apenas alguns professores estão há menos tempo de atuação na escola.

A primeira pergunta teve o intuito de verificar os sentimentos dos professores frente ao desafio de implementar o regime de estudos remoto emergencial, em meio às incertezas relacionadas ao desconhecimento do processo de ensino e aprendizagem de forma remota. Nossas análises revelam unanimidade traduzida em palavras como: insegurança, apreensão, receio, perplexidade, palavras que demonstram o quanto a migração abrupta da sala de aula presencial para o ensino remoto pode ser desafiadora. Vale lembrar nossa apreensão ao sermos surpreendidos por decretos municipais e estaduais no dia 16 de março de 2020, suspendendo as aulas presenciais por tempo indeterminado (decisão que se estendeu até o final do ano letivo). 
O sentimento de incerteza, angústia e insegurança é naturalmente compreensível, afinal, nunca estivemos diante de uma situação como tal. Para tentar solucionar o problema ou ao menos, amenizá-lo, foi implantado o regime de estudos remoto, ao que os professores demonstraram certa insatisfação (gráfico 4), pelo fato de que, para muitos deles, não terem sido preparados para o novo modelo.

Gráfico 4. Satisfação acerca do suporte oferecido pela escola/rede municipal de ensino para a implementação do ensino remoto emergencial.

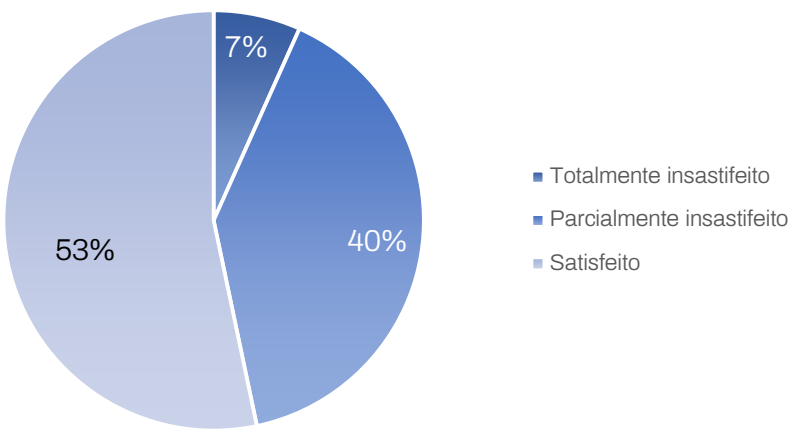

Fonte: Elaboração própria.

As declarações dos professores da EMPM não são exclusivas deste grupo de educadores. De acordo com pesquisa "Sentimento e percepção dos professores brasileiros nos diferentes estágios do Coronavírus no Brasil", publicada em setembro pelo Instituto Península (2020), a maioria dos professores se sentem sobrecarregados, cansados, estressados e frustrados diante da realidade das aulas remotas.

Ainda de acordo com a pesquisa, a maioria dos professores do ensino básico declara se sentir ansiosa, o que é uma consequência da abrupta transição para o ensino remoto, em um contexto de medo e preocupação geral devido à pandemia. Ainda conforme a pesquisa do instituto Península, mais de $80 \%$ dos professores da educação básica não possuía nenhuma experiência com aulas remotas e a maioria deles se sentia despreparada para ensinar remotamente.

Embora o processo de adaptação ao regime de ensino de estudos remoto tenha gerado frustrações, os professores declaram que o gerenciamento do tempo e a dedicação pessoal foram as principais potencialidades que contribuíram para a implementação do ensino remoto emergencial. O segundo ponto positivo foi o conhecimento tecnológico e as habilidades em plataformas ou aplicativos apresentados por alguns deles (gráfico 5). 
Gráfico 5. Principais potencialidades que contribuíram para a implementação do ensino remoto emergencial

a) Gerenciamento do tempo

b) Conhecimento tecnológico

c) Habilidade em plataformas/aplicativ...

d) Outras
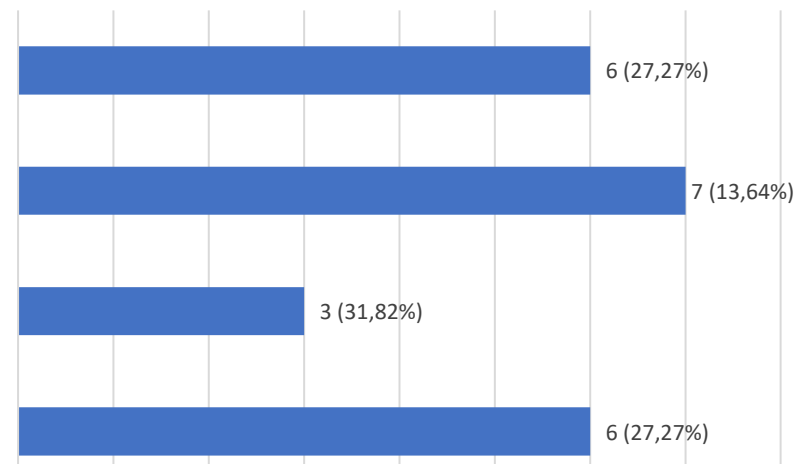

$3(31,82 \%)$

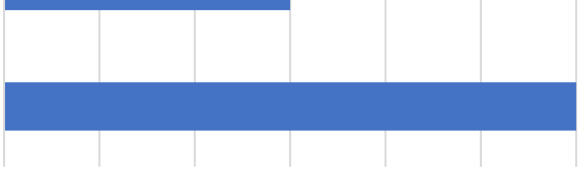

$6(27,27 \%)$

0

Fonte: Elaboração própria.

Já as principais dificuldades apontadas pelos professores foram maiores e mais abrangentes que as potencialidades. Entre as dificuldades mais citadas estão à falta de infraestrutura e conectividade, tanto dos profissionais, quanto de alguns alunos.

Gráfico 6. Principais dificuldades ou desafios relacionados ao ensino remoto emergencial

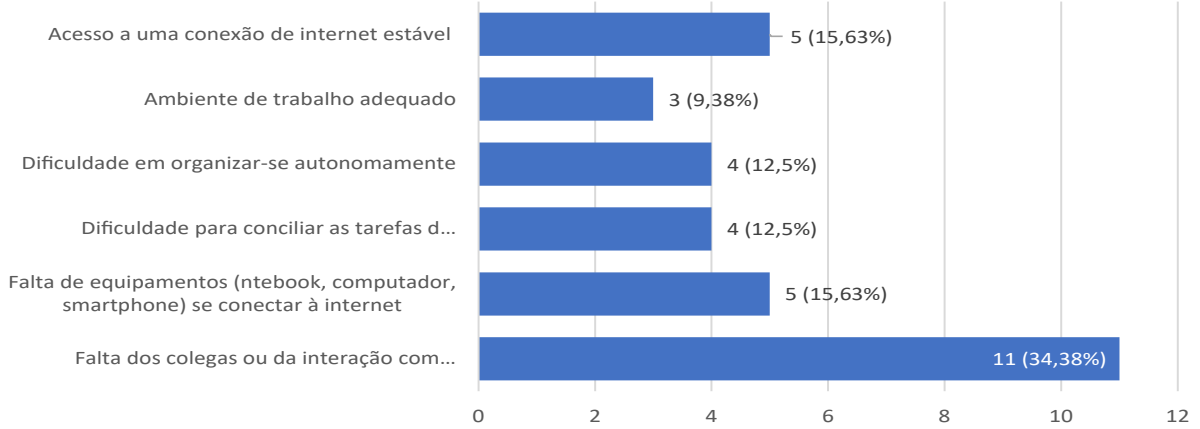

Fonte: Elaboração própria.

A perda do vínculo afetivo com os estudantes também se revelou como um obstáculo para a efetividade do ensino e aprendizagem no regime de estudos remoto. Lima (2021, p. 3) destaca a relevância dos vínculos afetivos e das ações compartilhadas para a nossa convivência social.

Somos seres sociais, dependemos de ações compartilhadas, de vários tipos de interação com o outro, das pessoas com quem mantemos relacionamento afetivo, bem como precisamos de um contexto cultural que nos dê suporte simbolicamente. 
Outros desafios foram a falta de formação e de conhecimento de ferramentas virtuais para lidar com os desafios impostos pela pandemia de Coronavírus, bem como a falta de um ambiente adequado para trabalhar em casa, informação também citada pelos professores como um dificultador. Muitos precisam conciliar as tarefas domésticas, o cuidado com filhos menores e a dedicação às tarefas profissionais, ao mesmo tempo. Por isso, é natural que a maioria dos professores se sintam angustiados e exauridos emocionalmente.

\section{Considerações finais}

Os estudantes do $9^{\circ}$ ano da EMPM em sua maioria, se envolveram ativamente no processo de ensino e aprendizagem, conduzidas por meio do regime de estudos remoto implementado em 2020, em decorrência da pandemia do Coronavírus. Grande parte deles demonstrou empenho e dedicação ao realizar as atividades contempladas nos cadernos de estudos, interagiu com os professores e com outros colegas por meio de aplicativos de mensagens como o WhatsApp, sanando dúvidas ou buscando explicações para os conteúdos escolares.

Entre os pontos positivos destacados, reiteramos a indicação para conteúdos virtuais, por meio de QR Codes e links indicadores de conteúdos auxiliares à compreensão das atividades escolares e das interações em áudio e vídeo por meio de aplicativos como WhatsApp.

Em síntese, as percepções dos professores da EMPM revelam suas principais dificuldades para lidar com o novo cenário educacional imposto pela pandemia. Contudo, em meio às turbulências, muitos desses profissionais também encontraram potencialidades pessoais que os auxiliaram a conduzir o ensino remoto de maneira mais produtiva e eficiente.

Dessa maneira, ressaltamos os cadernos de atividades implementados no regime de estudos remoto como uma importante ferramenta na condução deste. Contudo, há pontos que precisam ser revistos para buscar uma aprendizagem mais efetiva no regime de estudos remoto, entre os quais destacamos a necessidade de maior interação entre os professores e os alunos, e a implementação de aulas virtuais, sejam elas síncronas ou não.

A partir das experiências dos educadores e educandos com o período pandêmico e o distanciamento social, faz-se relevante pensar estratégias para o retorno à escola, considerando os sentimentos de ambos os envolvidos. Lima (2021, p.15) alerta que após o período pandêmico:

Os adultos da escola estarão ainda em situação de risco, portanto, precisam também seremacolhidos e respeitados em seu fazer pedagógico. Necessitarão de atualização constante sobre a evolução da pandemiae, consequentemente, fazer revisões das normas adotadas à medida que saiam novas informações.

A pandemia representou uma quebra no convívio social, afetando diretamente a escola, se apresentando como uma experiência desafiadora para qualquer pessoa. Como toda experiência, trouxe aprendizados para professores, alunos e as famílias. E, o ensino pós-pandemia promete possibilidades de mudanças, principalmente no 
que diz respeito ao uso das tecnologias. Esse retorno presencial abrirá um campo para investigações e futuras pesquisas baseadas em evidências, sobre os efeitos da pandemia.

\section{Referências}

Brasil. Medida Provisória no 934 de 01/04/2020.(2020). Recuperado de https://bit.ly/2V1boCm

Brasil (1996). Lei de Diretrizes e Bases da Educação Nacional 9.394, de 20 de dezembro de 1996. Recuperado de https://bit.ly/37a6zcc

Brumadinho (2015). Lei no 2145 de 17 de abril de 2015. Dispõe sobre a aprovação do Plano Decenal Municipal de Educação de Brumadinho/MG

Brumadinho (2020). Plano de ação de retorno às atividades educacionais remotas nas escolas municipais de Brumadinho, em meio à pandemia da COVID-19 do ano de 2020.

CEE (2020). Conselho Estadual De Educação de Minas Gerais. Resolução 474 de 08/05/2020. Recuperado de https://bit.ly/2Vk2wY6.

Instituto Península (2020). Sentimento e percepção dos professores brasileiros nos diferentes estágios de Coronavírus. Recuperado de https://bit.ly/3xbLcSy.

Leffa, V.J. (Org.) (2006) Pesquisa em Linguística Aplicada: temas e métodos. Pelotas: Educat.

Lima, E. de S. Currículo Emergencial para a educação durante e após a pandemia. Recuperado de https://bit.ly/3iZHITp.

Paiva, V. L. M. de O. (2019) Manual de pesquisa em estudos linguísticos. São Paulo: Parábola.

Como citar este artículo em APA:

Dutra, G. \& Souza, J. (2021). Ações implementadas no regime remoto ofertado por uma escola do sistema municipal de ensino de Brumadinho/MG para a garantia da continuidade da educação em resposta a pandemia. Revista Ibero-americana de Educação, 86(2), 95-112. https://doi.org/10.35362/rie8624395 